Toxicology

\section{Advances, challenges, and controversies in poisoning}

\section{A L Jones, P I Dargan}

\section{The treatment of self poisoned patients in the emergency} department

$\mathrm{P}$ atients presenting with self poisoning constitute a significant and increasing workload in emergency medicine departments and rates in the UK (up to 347 per 100000 per year) are among the highest in Europe. ${ }^{12}$ The severity of poisoning has decreased over the past decade with the introduction of safer drugs such as serotonin reuptake inhibitors over tricyclic antidepressants, but there are still more than 2000 deaths per year in the UK from self poisoning. ${ }^{3}$

\section{CHALLENGES IN CLINICAL TOXICOLOGY \\ Recognition of severe poisoning}

Fewer than $1 \%$ of people who present with self poisoning develop severe clinical effects. ${ }^{4}$ One of the main challenges in managing poisoned patients is to identify this group as early as possible so that appropriate supportive, and if necessary, specific management steps can be instituted to prevent serious complications. Equally importantly, the vast majority of patients (particularly children) require only supportive care and do not need to be exposed to unnecessary procedures. Meticulous supportive care is the most important aspect of the management of seriously poisoned patients. ${ }^{5}$ As a general rule complete elimination of a drug takes five half lives and seriously poisoned patients, who are often fit young adults, need to be kept alive to allow elimination of the drug. If organ failure ensues, extracorporeal removal of toxins may become necessary.

\section{Drugs of misuse}

Presentation to hospital with clinical effects from an ever growing number drugs of misuse is becoming more common, particularly in inner city areas. ${ }^{16}$ In addition to newer drugs such as GHB (gammahydroxybutyrate) combinations of drugs are often taken, for example, Sextasy (Ecstasy and Viagra). ${ }^{6}$ This issue of EMJ contains a reminder of the potential for methaemoglobinaemia from nitrite containing drugs of misuse such as "poppers". ${ }^{7}$ Cocaine use is increasing as the price of cocaine has fallen in several inner city areas. Cocaine misuse can result in cardiovascular complications such as myocardial ischaemia/ infarction, arrhythmias, and myocardial dysfunction. ${ }^{8}$ It is important that cocaine use is considered in all patients, especially young adults, presenting with acute coronary syndromes because this will change the management strategy. First line treatment for cocaine related myocardial ischaemia/infarction includes benzodiazepines and nitrates together with aspirin and oxygen; $\beta$ blockers are contraindicated and thrombolysis should not be used routinely because the mechanism is coronary artery vasospasm rather than thrombosis. ${ }^{58}$ Alcohol remains the most widely used "drug of misuse" throughout Europe and the impact of a blood ethanol concentration of greater than $0.50 \mathrm{~g} / \mathrm{l}$ on road accidents is shown by Fabbri et al. ${ }^{9}$

\section{Worldwide: issue of chemical preparedness}

The events of 11 September in the USA have alerted us to be more prepared for the unthinkable, including preparing for receiving victims exposed to biological or nerve warfare agents. ${ }^{10}$ Sarin exposure of the public in a subway happened in peacetime in Tokyo. ${ }^{11}$ Lessons learned from that tragedy included the need to have adequate decontamination facilities available, to avoid contamination of medical or nursing staff, and to have optimum procedures for admission and appropriate antidotal therapy for such patients. ${ }^{10}$ Further information is available from the UK Public Health Laboratory Service web site (http://www.phls.org.uk/facts/ deliberate releases.htm) and US Centers for Disease Control and Prevention website (http://www.bt.cdc.gov/Agent/ AgentlistChem.asp).

\section{Prevention of paracetamol poisoning}

Paracetamol is the commonest drug taken in overdose in the UK, accounting for $50 \%$ of all self poisoning episodes and 100-200 deaths per year. ${ }^{13}$ In September 1998 legislation was introduced in the UK limiting pack sizes available for sale in an attempt to decrease the number and severity of paracetamol overdoses. A number of studies have attempted to assess the impact of this legislation with conflicting findings and it is probably too early to tell whether it has had any clinically significant impact yet. ${ }^{12} \mathrm{~A}$ number of other measures have been considered to reduce paracetamol overdoses. However, few of these are practical and some, such as the addition of methionine have potential safety issues, which make them unsuitable. ${ }^{13}$ Prevention of paracetamol poisoning is a significant issue, but it is not, however, likely to be something that individual accident and emergency departments are going to be able to have a significant impact on.

\section{Optimising early care of poisoned patients}

The mainstay of gut decontamination in poisoning is the administration of activated charcoal within one hour of ingestion of a toxin..$^{14}$ However, recent studies have shown that as few as 15\% of patients are seen in hospital in the first hour after self poisoning, and further delays can occur during triage, waiting to see a doctor, and because of transport delays in more remote, rural areas. ${ }^{15}{ }^{16}$ It is important that those who have ingested a potentially serious overdose and have presented within the one hour interval are rapidly identified and "fast tracked" for activated charcoal therapy. Prehospital administration of charcoal by ambulance staff would allow earlier administration and may be one aspect of the future of the treatment of poisoned patients, though the potential risk of inducing vomiting and aspiration must be evaluated first.

\section{To do simple things well. For} example, weighing patients

The weight of patients is important in clinical toxicology because the toxic dose of many compounds is expressed in $\mathrm{mg} / \mathrm{kg}$ body weight and the dose of some drugs used to treat poisoned patients (for example, $\mathrm{N}$-acetylcysteine) is weight dependent. However, patients are often not weighed and doctors and nurses frequently estimate the weight of patients; these estimates of bodyweight are often inaccurate. ${ }^{17}$ A simple set of weighing scales should be standard equipment in all clinical areas treating poisoned patients and all patients presenting after taking an overdose should have a formal body weight measurement as a standard part of their management. All patients given medications based on bodyweight should also be formally weighed.

\section{RECENT ADVANCES IN CLINICAL TOXICOLOGY}

There have been a number of specific advances in the understanding of the mechanisms of poisoning and management of patients with poisoning over the past five years. 


\section{Improved understanding of mechanisms in poisoning, for example, late paracetamol poisoning}

The mechanism of toxicity in early paracetamol poisoning is well established and $\mathrm{N}$-acetylcysteine (NAC) protects against hepatotoxicity in these patients. ${ }^{18}$ Until recently, comparatively little was known about the mechanisms of toxicity in late paracetamol poisoning (more than 15 hours after ingestion). Recent studies have shown that factors such as production of cytokines and chemokines, nuclear transcription factors, free radicals, and caspases are involved in hepatotoxicity in late paracetamol poisoning..$^{18} \mathrm{NAC}$ is less effective in late paracetamol poisoning, ${ }^{18}$ and knowledge of the mechanisms of liver injury, at the haemodynamic and subcellular level, is important in the development of new treatments for paracetamol overdose, particularly for patients who present late. However, until these new treatments are available NAC remains the treatment of choice in patients presenting with late paracetamol poisoning. ${ }^{18}$

\section{New antidotes, for example, 4-methylpyrazole in ethylene glycol and methanol poisoning}

Ethylene glycol and methanol are metabolised to toxic metabolites by alcohol dehydrogenase and significant clinical effects including metabolic acidosis, CNS depression, and acute renal failure can occur in overdose. The mainstay of management is inhibition of alcohol dehydrogenase and thus reduction of toxic metabolite formation. ${ }^{19}$ Until recently the only agent available was ethanol, but treatment with ethanol causes CNS depression and hypoglycaemia and requires close laboratory monitoring of blood ethanol concentrations. ${ }^{19}$ A new alcohol dehydrogenase inhibitor is now available: 4-methylpyrazole (4-MP, fomepizole). 4-MP is well tolerated and blood concentrations are not required to monitor treatment; the main drawback of 4-MP is its cost of $£ 1000-£ 2000$ per treatment course. There have been three recently published multicentre prospective case series describing the successful use of 4-MP in adults with ethylene glycol and methanol poisoning. ${ }^{20-22}$ There have been no trials comparing ethanol and 4-MP and until these data are available, ethanol is generally the antidote of choice in ethylene glycol and methanol poisoning. However, there are certain circumstances where we would advocate the use of 4-MP. For example, in asymptomatic patients (particularly children) who present early after a witnessed large ingestion with biochemical evidence of poisoning (a raised osmolal gap, or if available a raised methanol/ethylene glycol concentration) and potentially in patients who have coingested CNS depressants, in whom additional CNS depression would be difficult to manage.

Novel treatment methods, for example, Haemofiltration, Molecular Adsorbent Recycling System (MARS) Extracorporeal drug removal techniques such as haemoperfusion and haemodialysis are indicated in a minority of severe cases of poisoning. ${ }^{23}$ However, each technique has problems such as limited availability, poor tolerance in haemodynamically compromised patients, and poor removal of protein bound drugs. ${ }^{23}$

Haemofiltration is available in most intensive care units and is better tolerated in hypotensive patients but there are limited data on the use of haemofiltration in poisoned patients. Recent, in vitro studies have shown significant removal of salicylate by haemofiltration ${ }^{24}$ but further work is required before it can be recommended in the management of poisoned patients

MARS is an extracorporeal device that combines conventional haemodialysis with a secondary system containing an albumin impregnated dialysis membrane (with an albumin containing dialysate) in addition to anion-exchange and charcoal columns. ${ }^{25}$ It has been used in the management of acute liver failure ${ }^{25}$ and because it is able to remove protein bound substances could theoretically be used in the management of severe poisoning with highly protein bound drugs such as salicylates in the future, but for now it remains a research tool in the few centres in which it is available.

\section{Better training: greater availability of information and courses}

In the UK, several databases have been developed to meet the increasing needs of doctors and nurses for easy access to information on poisoning. TOXBASE (http://www.spib.axl.co.uk/), a computerised database run by the National Poisons Information Service, has been available over the internet to health professionals in the UK since 1999, having replaced the former Viewdata database of the same name that was developed in the 1970s. ISABEL (http://www. isabel.org.uk/) is a new medical information system, also delivered via the internet, that provides support in diagnosis and management of children and includes toxicology as one of its components. As well as an aid to the management of individual patients, both of these web sites can be used as an educational tool.

Poisoning is an important part of the workload in emergency medicine, general medicine, and intensive care. NPIS centres offer a wide range of training courses for doctors and nurses in all of these disciplines; details of these courses are available on TOXBASE (http:// www.spib.axl.co.uk/).
THE FUTURE: DEVELOPMENT OF AN EVIDENCE BASE FOR THE MANAGEMENT OF POISONED PATIENTS

Guidelines for the management of poisoned patients should be evidence based. ${ }^{26}$ However, the level of evidence in toxicology is often poor and based on case reports/series or observational studies that have been performed on highly selected patients and so are subject to significant bias. There has been little hypothesis testing research performed in toxicology. Many management strategies have been developed as an extrapolation from the pharmacological effects of drugs or from animal data or generalisations from drugs within the same class, which is far from satisfactory.

There are a number of questions that need to be answered, including whether various gut decontamination methods have an impact on the outcome of patients with severe poisoning. In addition, there are a number of specific issues to be addressed such as the indications for hyperbaric oxygen in carbon monoxide poisoning, the optimum regimen and mechanism of action of sodium bicarbonate in tricyclic antidepressant poisoning, management of late paracetamol poisoning, and length of treatment with deferoxamine in iron poisoning to name but a few.

Clinicians in poisons centres need to work with those working in emergency medicine to develop modern, evidence based practice that recognises the sensitivity of this group of patients and their special needs. Large, multicentre studies across many hospitals in different regions are needed to study outcomes and treatment strategies and to collect data to optimise the management of poisoned patients. Let us hear from you and we can get started!

Emerg Med J 2002;19:190-191

\section{Authors' affiliations}

A L Jones, P I Dargan, National Poisons Information Service, Guy's and St Thomas' NHS Trust, Avonley Road, London, SE 14 5ER, UK

Correspondence to: $\operatorname{Dr} \mathrm{A} L$ Jones; alison.jones@gstt.sthames.nhs.uk

\section{REFERENCES}

1 Townsend E, Hawton K, Harriss L, et al. Substances used in deliberate self-poisoning 1985-1997: trends and associations with age, gender, repetition and suicide intent. Soc Psychiatry Psychiatr Epidemiol 2001;36:228-34.

2 Michel K, Ballinari $P$, Bille-Brahe U, et al. Methods used for parasuicide: results of the WHO/EURO multicentre study on parasuicide. Soc Psychiatry Psychiatr Epidemiol 2000;35: 156-63.

3 Hawton K, Townsend E, Deeks J, et al. Effects of legislation restricting pack sizes of paracetamol and salicylate on self- poisoning in the UK: before and after study. BM 2001;322:1203-7. 
4 Litovitz TL, Klein-Schwartz W, White S, et al. 2000 Annual report of the American Association of Poison Control Centers Toxic Exposure Surveillance System. Am J Emerg Med 2001;19:337-95.

5 Jones AL, Dargan PI. Churchill's pocketbook of toxicology. Edinburgh: Churchill Livingstone, Harcourt, 2001.

6 Jones AL, Volans G. Recent advances: management of self-poisoning. BM 1999:319:1414-17.

7 Modaria B, Kapadia YK, Kerins M, et al. Methylene blue: a treatment for severe methaemoglobinaemia secondary to misuse of amyl nitrate. Emerg Med J 2002;19:271-2.

8 Lange RA, Hillis LD. Medical progress: cardiovascular complications of cocaine use. NEJM 2001;345:351-8.

9 Fabbri A, Marchesini G, Morselli-Labate AM, et al. Positive blood alcohol concentration and road accidents. A prospective study in an Italian emergency department. Emerg Med J 2002;19:210-14.

10 Flanagan RJ, Jones AL. Antidotes. London: Taylor-Francis, 2001

11 Okumura T, Suzuki K, Fukuda A, et al. The Tokyo subway Sarin attack disaster management. Part 2; Hospital report. Acad Emerg Med 1998;6:618-24.
12 Dargan PI, Jones AL. The impact of paracetamol pack-size legislation on paracetamol poisoning. J Evidence Based Healthcare 2001;5:117-18.

13 Norman E, Dhairiwan R, Dargan PI, et al. Paracetamol poisoning: can it be prevented? Proc R Coll Physicians Edinb 2001;31:62-5.

14 American Academy of Clinical Toxicology \& European Association of Poisons Control Centres and Clinical Toxicologists. Position statement: Single-dose activated charcoal. J Toxicol Clin Toxicol 1997;35:721-41.

15 Thakore S, Murphy N. The potential role of prehospital administration of activated prehospital administration of activated
charcoal. Emerg Med J 2002;19:63-5.

16 Karim A, Ivatts S, Dargan PI, et al. How feasible is it to conform to the European guidelines on the administration of activated charcoal within one hour of overdose? Emerg Med J 2001:18:390-2.

17 Dargan PI, Shin GY, Jones AL. How well do doctors and nurses estimate the weight of patients? J Toxicol Clin Toxicol 2001;39:567-8.

18 Jones AL. Recent advances in the management of late paracetamol poisoning. Emergency Medicine (Australia) 2000;12:14-21.

19 Brent J. Current management of ethylene glycol poisoning. Drugs 2001;61:979-88.
20 Brent J, McMartin K, Phillips S, et al. Fomepizole for the treatment of ethylene glycol poisoning. N Engl J Med 1999;340:832-8.

21 Borron SW, Megarbane B, Baud FJ. Fomepizole in the treatment of uncomplicated ethylene glycol poisoning. Lancet 1999;354:831.

22 Brent J, McMartin K, Phillips S, et al. Fomepizole for the treatment of methanol poisoning. N Engl J Med $2001 ; 344: 424-9$.

23 Pond S. Extracorporeal techniques in the treatment of poisoned patients. Med J Aust 1991;154:617-22.

24 Dargan PI, Jones AL, Salimi Gilani P, et al. Hemofiltration-a potential new treatment for salicylate poisoning. J Toxicol Clin Toxicol $2001 ; 39: 483$

25 Strange J, Mitzner SR, Risler T, et al. Molecular Adsorbent Recycling System (MARS): clinical results of a new membrane-based blood purification system for bioartificial liver support. Artif Organs 1999;23:319-30.

26 Wallace $\mathrm{Cl}$, Dargan $\mathrm{PI}$, Jones $\mathrm{AL}$. Paracetamol overdose: an evidence based flowchart to guide management. Emerg Med 2002; 19:202-5

Toxicology

\section{Troublesome toxins}

\section{A Parfitt, J A Henry}

\section{The treatment of patients with acute poisoning admitted to the emergency department is discussed}

A cute poisoning now accounts for about $3 \%-5 \%$ of emergency department attendances in most countries with developed medical services. ${ }^{12}$ Each patient presents a challenge to the skills of the doctor, who has to deal not only with the toxic effects of the poison but also with the mental state of the patient, anxious parents, friends or relatives. Because of this, many doctors find the poisoned patient more difficult to deal with than a "straightforward" medical or surgical case. Here we consider a few current topics in poisoning.

\section{GASTROINTESTINAL DECONTAMINATION}

Some junior doctors still think that a decision not to empty the stomach might lead to an appearance in the coroner's court. However, there is no evidence that reducing absorption of ingested toxins shortens the duration of admission to hospital or saves life. ${ }^{3}$ Syrup of ipecacuanha, although an effective emetic, does not effectively empty the stomach and should not be used. Gastric lavage also has drawbacks and may force poisons through the pylorus into the proximal small intestine. ${ }^{4}$ Consensus of expert opinion in Europe and the USA considers activated charcoal the preferred treatment for most poisons within one hour of ingestion. ${ }^{2}{ }^{3}$ Karim et al have recently drawn attention in this journal to time constraints in the administration of charcoal, while Wolseley et al in the USA have noted that patients brought to hospital by ambulance are given charcoal earlier after arrival. ${ }^{56}$ The other treatment deserving consideration in special circumstances is whole bowel lavage, which uses a large amount of isotonic fluid (as in bowel preparation for radiological procedures) to empty the gut by "flushing out" the intestinal contents. This technique is of special use for sustained release preparations (such as lithium, theophylline, and propranolol), heavy metal compounds, iron, and illicit drug packets in body packers. ${ }^{7-10}$ The technique is less disturbing to the patient than might be imagined and flavoured formulations exist for children. This brief look at methods of intestinal decontamination will hopefully encourage hospital doctors to revise their knowledge concerning the appropriate methods for use in their own environment. $^{23}$

\section{CLINICAL ISSUES IN PARACETAMOL POISONING}

Paracetamol is still the commonest substance taken in overdose in Britain, and in many places paracetamol ingestion forms $50 \%$ of all poisoning cases seen. ${ }^{2}$ Despite a clear exposition on management in the British National Formulary and the availability of guidelines and posters from the British Association for Accident and Emergency Medicine, paracetamol remains the commonest cause of enquiries to the United Kingdom National Poisons Information Service in both adults and children. ${ }^{11}{ }^{12}$ It is important to be aware that the great majority of overdose cases will be asymptomatic when seen, so that every patient requires a plasma paracetamol level at least four hours after ingestion in order to decide on the need for treatment.

What are the main things that the "doctor at the door" needs to know about paracetamol? Firstly, that we have highly effective antidotes, provided they are given within about 10 hours of ingestion. Secondly, the decision to treat is based on a nomogram involving time since ingestion of a single overdose and the plasma paracetamol level. Thirdly, that it is safer to give the antidotes than not to give them unless one can be completely sure of the history, the timing of ingestion and the blood level-if there are confounding issues, such as a staggered overdose or an unreliable history, the patient must be treated. And fourthly, one has to determine whether the patient falls into a "high risk" category, so that the patient must be treated at lower blood paracetamol levels as the current guidelines indicate. Knowledge of these simple facts alone should enable the great majority of cases to be treated effectively without the need for further advice. 


\section{CARBON MONOXIDE}

Carbon monoxide is still the commonest cause of poisoning deaths in the United Kingdom. In the emergency department, acute and subacute exposure are important presentations to recognise and treat. Many departments in the UK wisely teach on the common and non-specific symptoms that result from poisoning at the start of the winter months. Treatment is controversial. Publication of the first double blind trial of hyperbaric oxygen in carbon monoxide poisoning in the Australian Journal of Medicine has cast doubt on the usefulness of hyperbaric therapy, ${ }^{13}$ but a further study as yet only published in abstract form is likely to show that it is effective (LK Weaver, et al, UHMS Annual Scientific Meeting Session Texas, 2001). Many recommend hyperbaric oxygen in those who have lost consciousness, those with a blood carboxyhaemoglobin over $20 \%$ on arrival, the pregnant patient and those with neurological or electrocardiographic changes. Hyperbaric centres are available for expert consultation and generally rely on the clinical picture to reach a decision regarding treatment.

\section{CYANIDE}

Although rare, acute cyanide poisoning requires immediate action. Many patients suffering from smoke inhalation or burns may also have cyanide toxicity, and may present with a metabolic acidosis not responding to oxygen administration. Different antidotes are used in different countries, cobalt edetate (UK) and sodium nitrite (USA) are the commonest, each with its drawbacks, while sodium thiosulphate is slower acting but harmless. There is now a further antidote, hydroxocobalamin. ${ }^{15}{ }^{16}$ This drug should be more widely used because it may be especially useful in patients with smoke inhalation, as it is not toxic and can be given outside the hospital.

\section{CONCLUSION}

The scene changes from time to time. We have tried to point out a few of the developments in poisoning where changes are taking place. Hippocrates is reputed to have said "Primum non nocere" (first of all do not cause harm). Many dramatic interventions are available, but the risk-benefit balance has to be borne in mind so that the patient recovers as a result of good medicine.

Emerg Med J 2002;19:192-193

....................

\section{Authors' affiliations}

A Parfitt, J A Henry, Academic Department of Accident and Emergency Medicine, Imperial College School of Medicine, St Mary's Hospital, London W2 INY, UK

Correspondence to: Professor J A Henry; j.a.henry@ic.ac.uk

\section{REFERENCES}

Greaves I, Goodacre S, Grout P. Management of drug overdose in $A$ and $E$ departments in the United Kingdom. J Accid Emerg Med 1996;13:43-8.

2 Jones Al, Volans G. Management of self poisoning. BM 1999;319:1414-17.

3 Henry JA, Hoffman JR. Continuing controversy in gut decontamination. Lancet 1998;352:420-1.

4 Saetta JP, March S, Gaunt ME, et al. Gastric emptying procedures in the self poisoned patient: are we forcing gastric content beyond the pylorus? J R Soc Med 1991;84:274-6.
5 Karim A lvatts S, Dargan $P$, et al. How feasible is it to conform to the European guidelines on administration of activated charcoal within one hour of an overdose? Emerg Med J 2001;18:390-2.

6 Wolseley BA, McKinney PE. Does transportation by ambulance decrease time to gastrointestinal decontamination after overdose? Ann Emerg Med 2000;35:579-84.

7 American Academy of Clinical Toxicology and European Association of Poison Contro Centres and Clinical Toxicologists. Position statement: single dose activated charcoal. Clin Toxicol 1997;35:721-41.

8 American Academy of Clinical Toxicology and European Association of Poison Contro Centres and Clinical Toxicologists. Position statement: whole bowel irrigation. Clin Toxicol 1997; 35:753-62.

9 Caruana DS, Weinbach B, Goerg D, et al. Cocaine packet ingestion: diagnosis, management and natural history. Ann Intern Med 1984;100:73-4.

10 Tenenbein $M$. Whole bowel irrigation as a gastrointestinal decontamination procedure after acute poisoning. Medical Toxicology 1988;3:77-84

11 BMA/RPSGB. British National Formulary. No 42. London: British Medical Association/ Royal Pharmaceutical Society of Great Britain 2001.

12 Bialas MC, Evans RJ, Hutchins AD, et al The impact of nationally distributed guidelines on the management of paracetamol poisoning in accident and emergency departments. J Accid Emerg Med 1998:15:13-17.

13 Scheinkestel CD, Bailey M, Myles PS, et al. Hyperbaric or normobaric oxygen for acute carbon monoxide poisoning a randomised controlled trial. Med J Aust 1999;170:20310 .

14 Weaver LK. Hyperbaric oxygen in carbon monoxide poisoning. BM 1999;319:1083-

5 Houeto P, Hoffman JR, Baud FJ, et al. Relation of blood cyanide to plasma cyanocobalamin concentration after a fixed dose of hydroxocobalamin in cyanide poisoning. Lancet 1995;346:605-8.

16 Beasley DM, Glass WI. Cyanide poisoning: pathophysiology and treatment recommendations. Occup Med 1998;48:427-31. 


\section{Introduction to the research series}

A M T Good, P Driscoll

This short editorial introduces the series on research in emergency medicine that starts in this issue

t was Sir William Osler who said that visiting patients without having read medicine was like going to sea without maps. One might say this of research. Most doctors enter higher specialist training with only a rudimentary knowledge of how to conduct a scientific study. Those that decide to take up an academic post will have a supervisor (or navigator) to help them though planning their research and negotiating the difficulties that arise.
Unfortunately for the majority of those who undertake research in emergency medicine no such luxury is available. They therefore often set off without proper preparation, the ability to deal with difficulties that arise or even a clear destination. Some if not many give up disillusioned.

The objective of this series of 10 articles is to help disseminate the wisdom that is often held in established research centres. Such a series cannot fully substitute for undertaking a course of research under good supervision. It does however provide guidance on how to go about emergency medicine research and discuss solutions to the common difficulties encountered.

We offer therefore a starting point. It is hoped that in time this series will be supplemented with further well informed articles. This then will add to the pool of knowledge available to facilitate high quality emergency medicine research. To provide not only the maps and confidence to approach experienced navigators but also a well founded enthusiasm for going to sea.

\section{Authors' affiliations}

A M T Good, Royal Liverpool University Hospital, Prescot Street, Liverpool L7 8XP, UK P Driscoll, Hope Hospital, Salford, UK

Correspondence to: Dr A M T Good

\section{Anaesthetic machines in the accident and emergency resuscitation room}

D lease ensure that any anaesthetic machine used in the accident and emergency resuscitation room complies with safety notice MDA SN2001(15).

Recommendations

- All anaesthetic machines used in A\&E must be equipped with a hypoxic mixture guard with an audible alarm to prevent the delivery of a gas mixture containing less than $20 \%$ oxygen to a patient.

- No practitioner should use an anaesthetic machine unless they have been trained and are competent in its use. All anaesthetic machines must be checked regularly and before each use by an authorised person.

M J Clancy

on behalf of FAEM and BAEM 